\title{
Antipsychotic Use During Pregnancy and Risk for Gestational Diabetes: A National Register-Based Cohort Study in Sweden
}

\author{
Essi Heinonen ${ }^{1,2}$ (1) $\cdot$ Lisa Forsberg ${ }^{1} \cdot$ Ulrika Nörby $^{3,4} \cdot$ Katarina Wide $^{1,5} \cdot$ Karin Källén $^{3}$
}

Accepted: 17 February 2022 / Published online: 26 February 2022

(c) The Author(s) 2022

\begin{abstract}
Objective We aimed to study whether antipsychotic use during pregnancy is associated with gestational diabetes. Methods This was a Swedish national register-based cohort study on the Medical Birth Register and the Prescribed Drug Register including all 1,307,487 singleton births between July 2006 and December 2017. Antipsychotics were divided into first-generation antipsychotics $(n=728)$, high-risk metabolic second-generation antipsychotics including olanzapine, clozapine and quetiapine $(n=1710)$, and other second-generation antipsychotics $(n=541)$. The risks for gestational diabetes, foetal growth disturbances, pre-eclampsia, caesarean section and preterm labour were assessed. Women treated during pregnancy were compared to women not treated during pregnancy and to women who used antipsychotics before/after but not during pregnancy.

Results The crude risk ratio for gestational diabetes for women treated with high-risk metabolic second-generation antipsychotics during pregnancy was 2.2 (95\% confidence interval [CI] 1.6-2.9) compared to untreated pregnant women $(n=$ $1,296,539)$ and 1.8 (95\% CI 1.4-2.5) compared to women treated before/after pregnancy ( $n=34,492)$. After adjustment for maternal factors including body mass index, the risk ratios were 1.8 (95\% CI 1.3-2.4) and 1.6 (95\% CI 1.2-2.1). Exposed infants had an increased risk of being large for gestational age: adjusted risk ratios 1.6 (95\% CI 1.3-1.9) and 1.3 (95\% CI 1.1-1.6) compared to no maternal antipsychotic use during pregnancy and maternal use before/after the pregnancy. Other antipsychotics were not associated with metabolic risks.

Conclusions Olanzapine, clozapine and quetiapine used during pregnancy were associated with increased risks for gestational diabetes and the infant being large for gestational age. Enhanced metabolic monitoring should be considered for pregnant women using these drugs.
\end{abstract}

\section{Plain Language Summary}

The use of second-generation antipsychotics amongst pregnant women is increasing. The side effects of these drugs, for example weight gain and increased blood sugar, are well described for the general population. In particular, olanzapine, quetiapine and clozapine are known to cause these effects. Studies on their effects on blood sugar control in pregnant women have however been conflicting. Pregnancy itself also imposes a risk for increased blood sugar levels and gestational diabetes. The purpose of this study was to evaluate the risk of gestational diabetes connected to the use of antipsychotics during pregnancy. The study was nationwide and register based including 1.3 million births in Sweden between July 2006 and December 2017. The rates of gestational diabetes and the infants being small for gestational age or large for gestational age amongst women treated with antipsychotics were compared to the rates in pregnant women who did not receive antipsychotics and to rates in a control group of women treated with antipsychotics before/after but not during pregnancy. Antipsychotics were divided

Essi Heinonen

essi.heinonen@ki.se

1 Division of Paediatrics, Department of Clinical Science, Intervention and Technology (CLINTEC), Karolinska Institutet, 14157 Stockholm, Sweden

2 Department of Paediatrics, Unit of Neonatology at Karolinska University Hospital, Stockholm, Sweden
3 Department of Clinical Sciences, Centre of Reproduction, Epidemiology, Tornblad Institute, Lund University, Lund, Sweden

4 Health and Medical Care Administration, Region Stockholm, Stockholm, Sweden

5 Department of Pediatrics, Unit of Emergency Pediatrics at Karolinska University Hospital, Stockholm, Sweden 
into three groups: (i) first-generation antipsychotics, (ii) high-risk second-generation antipsychotics including olanzapine, quetiapine and clozapine, and (iii) other second-generation antipsychotics. Women treated with high-risk second-generation antipsychotics were found to have an increased risk of gestational diabetes and giving birth to an infant being large for gestational age, both when compared with untreated pregnant women and with the control group. Other antipsychotics were not connected to increased risks of these outcomes. Hence, pregnant women treated with olanzapine, quetiapine or clozapine should be monitored regarding blood sugar levels.

\section{Key Points}

Use of olanzapine, clozapine and quetiapine during pregnancy is associated with an increased risk for the metabolic complications of gestational diabetes and infant being large for gestational age.

These risks are not a reason for discontinuing an ongoing treatment but enhanced metabolic monitoring should be considered during pregnancy.

If treatment with antipsychotics is started during pregnancy or in a woman planning a pregnancy, prescription of other antipsychotics may be preferable from a metabolic point of view.

\section{Introduction}

The use of second-generation antipsychotic drugs (S-GAs) has more than doubled in the last decade, mainly explained by a wider spectrum of indications than for the first-generation antipsychotics (F-GAs), for example bipolar disorder [1-7]. The S-GAs have less extrapyramidal and prolactin-related side effects than F-GAs, but there are concerns regarding their metabolic side effects [8-13]. Clozapine, olanzapine and quetiapine have the most prominent metabolic side effects, including significant weight gain, whereas aripiprazole has weight loss as a common side effect $[8,14]$.

The prevalence of gestational diabetes (GDM) is increasing, with a huge geographic variation between 2 and $23 \%$ within Europe, likely mainly owing to differing diagnostic criteria between countries $[15,16]$. Predisposing factors for GDM are obesity, family history of diabetes, increasing parity, unhealthy diet, sedentary lifestyle and lower socioeconomic status, many of which are overrepresented in women treated with antipsychotics [17-21]. Hyperglycemia in expectant mothers caused by untreated or unnoticed diabetes mellitus leads to increased transplacental glucose transfer, which causes foetal hyperinsulinism. As insulin is a major growth factor, this causes increased foetal growth and the infant being large for gestational age (LGA). Women with LGA infants are at risk for delivery complications such as shoulder dystocia and emergency caesarean section, and the infants are at risk for neonatal hypoglycaemia and treatment at a neonatal intensive care unit. Gestational diabetes is also a risk factor for pre-eclampsia in the mother and type 2 diabetes mellitus later in life for both the mother and child [22-27]. In Sweden, practices regarding screening for GDM vary between regions and women are usually not screened with an oral glucose tolerance test, unless they have risk factors or a pathological random blood glucose test [28, 29].

Studies on the association between antipsychotic use during pregnancy and GDM are conflicting. Some have shown an increased risk for GDM [7, 10, 19, 21, 30, 31], not confirmed by others [16, 32-35]. Increased risks for prematurity and the infant being small for gestational age (SGA) and LGA have also been shown [10, 21, 32, 36-38]. The metabolic effects of antipsychotics seem difficult to separate from the risks of the underlying disease and lifestyle [16, 33, 34]. Changing an effective antipsychotic during pregnancy is not recommended, as treatment discontinuation increases the risk of relapse, which is harmful for both mother and child [39-41]. The primary objective of this study was to investigate whether the different groups of antipsychotics were associated differently with metabolic complications and whether the women treated during pregnancy had an increased risk for pregnancy complications when compared to the control group of women who used antipsychotics before or after but not during the actual pregnancy.

\section{Methods}

The study was a register-based study using prospectively collected data, combining data from the Swedish Medical Birth Register (MBR) [42] and the Prescribed Drug Register [43]. Swedish personal identification numbers were used for linkage between the registers. The MBR was used to collect information about maternal and foetal background characteristics as well as the main outcome GDM. The MBR contains data from the delivery, the paediatric examination of the newborn and antenatal care including body mass index (BMI), medications and smoking habits registered in the first trimester for $>97 \%$ of all births.

The study population consisted of all singleton births in Sweden, a total of $1,307,487$ infants, registered in the MBR between 1 July, 2006 and 31 December, 2017. After 
exclusion of pregnancies with pre-pregnancy diabetes, defined as International Classification of Diseases codes $\mathrm{O} 24.0, \mathrm{O} 24.1, \mathrm{O} 24.3$ and $\mathrm{O} 24.8$ and women using valproic acid during pregnancy, a total of 1,299,216 pregnancies were included in the search. Users of valproic acid were excluded because of its known teratogenicity and metabolic side effects [44]. An outline of the study design is presented in Fig. 1.

\subsection{Drug Exposure}

Exposure data for prescription drugs were acquired from both the MBR and the Prescribed Drug Register. The Prescribed Drug Register stores data on drugs prescribed in ambulatory care and dispensed at Swedish pharmacies but does not include medications used in hospitals for in-patient care. The MBR includes drug use reported at the first visit at the maternal care centre, usually in the first trimester. The drugs are classified according to the Anatomical Therapeutic Chemical classification system. Drugs belonging to Anatomical Therapeutic Chemical class N05A were included. Exposures to dixyrazine (N05AB01), prochlorperazine (N05AB04), melperone
(N05AD03) and lithium (N05A N01) were excluded because their indications for use and pharmacological properties differed from the other antipsychotics. The included antipsychotics were divided into F-GAs mainly consisting of levomepromazine, haloperidol and flupentixol, $n=728$, high metabolic risk S-GAs (HR S-GAs) including quetiapine $(n=1026)$, olanzapine $(n=771)$ and clozapine $(n=29)$, and other S-GAs including aripiprazole $(n=334)$, risperidone $(n=191)$, ziprasidone ( $n$ $=34)$, paliperidone $(n=9)$ and sertrindole $(n=2)$. The different antipsychotics were not compared to each other because of the small numbers of exposures to individual antipsychotics.

The drug exposure was allocated into any use (drugs dispensed at any time during pregnancy including 1 month before the pregnancy), late use (drugs dispensed during the last 90 days of the pregnancy with or without earlier dispenses) and early use only (dispensed 1 month before and during pregnancy but not during the last 90 days of the pregnancy) to explore whether the timing of the drug use was connected to the risk of GDM. Timing was used as a proxy for the duration of antipsychotic treatment. We also created a comparison group with

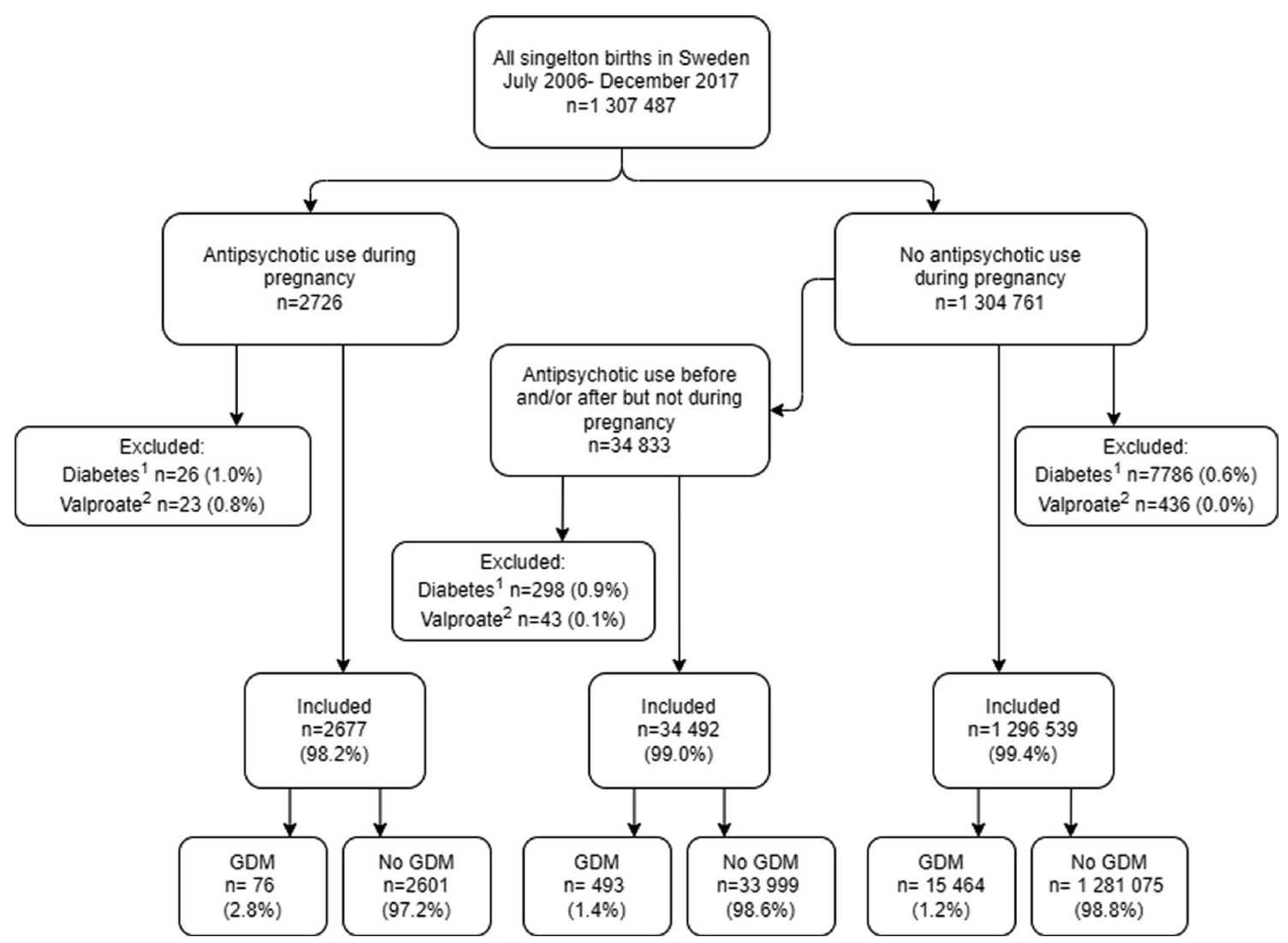

Fig. 1 Flowchart over the study design. ${ }^{1}$ Women with pre-pregnancy diabetes mellitus (type 1 or 2 ). ${ }^{2}$ Use of valproate during pregnancy. GDM gestational diabetes 
women treated with antipsychotics at any time during the study period but not during the interval of 1 month before the actual pregnancy to delivery, attempting to control for the effect of the underlying psychiatric illness and its associated psychosocial background factors. The women treated during pregnancy were compared to both this control group and to all women not treated during pregnancy, including the control group. Exposure data were also collected for other psychotropic drugs: antidepressants (N06A), antiepileptics (N03A), opioids (N02A), lithium (N05A N01), centrally acting sympathomimetics (N06B), sedatives and anxiolytics (N05B and N05C), and milder sedatives and antiemetics including promethazine (R06AD02, R06AD52), alimemazine (R06AD01), dixyrazine (N05A B01), prochlorperazine (N05A B04) and melperone (N05A D03). These drugs are presented in Table 1 and were adjusted for in a separate analysis.

\subsection{Maternal and Pregnancy Outcomes}

The maternal and pregnancy outcomes were extracted from the MBR, where diagnoses are registered according to the International Classification of Diseases, 10th Edition. The main outcome GDM was defined as a recorded International Classification of Diseases, 10th Edition code of O24.4 during pregnancy. The secondary outcomes were the infant being LGA $(Z$-score $>2$ standard deviations) or SGA ( $Z$-score $<-2$ standard deviations) measured with $Z$-scores based on infant weight for gestational age and sex [45], pre-eclampsia (yes/no), caesarean section (acute or planned, vs vaginal birth), gestational age (classified as <32 weeks, 32-36 weeks, 37-41 weeks, $\geq 42$ weeks, with the reference being normal gestational age of 37-41 weeks) and perinatal death (vs survival).

\subsection{Statistical Analyses}

Risk ratios (RRs) were obtained for all dichotomous outcomes: GDM vs no GDM, LGA vs appropriate for gestational age, SGA vs appropriate for gestational age, preeclampsia vs no pre-eclampsia, caesarean section (acute/ planned) vs vaginal birth, premature labour/prolonged pregnancy vs normal gestational age (37-41 weeks) and perinatal death (vs survival) by using modified Poisson regression in multivariate regression models. Crude and adjusted RRs were calculated. Robust standard error estimation was used to correct for time-invariant confounding. The exposures were any antipsychotic use vs no use, use of the different antipsychotic groups vs no use, late use vs early use only, and use during vs use before or after pregnancy. In the final analyses, adjustments were made for maternal factors: maternal age (continuous), primiparity (vs multiparity), maternal smoking (ordinal: $1=$ no smoking, $2=$ smoking $<10$ cigarettes/day, $3=$ smoking $\geq 10$ cigarettes/day, entered as a continuous variable), BMI (continuous). Maternal use of other neurotropic drugs was added to the list of adjusted factors in a sensitivity analysis on GDM, LGA and SGA. The role of BMI was explored through a separate model where BMI was not adjusted for, and by performing sensitivity analyses obtaining BMI-strata-specific risk estimates (classes: $\mathrm{BMI}<25$, BMI 25-30 and BMI >30). Missing data regarding maternal smoking and BMI were replaced by the overall means because of the large sample size and low percentage of missing data. Testsof homogeneity of the adjusted RRs across BMI strata were based on weighted sums of the squared deviations of the stratum-specific logRRs from their weighted means. For descriptive data, chisquare tests were used to detect heterogeneity between exposure groups. The statistical analyses were conducted using SPSS version 27 (IBM SPSS Statistics, IBM Corporation, Armonk, NY, USA).

\section{Results}

Maternal background characteristics for women treated with antipsychotics during pregnancy, before and/or after but not during pregnancy and women not treated with antipsychotics during pregnancy are described in Table 1 . There were 2677 individual pregnancies during which the women were treated with an antipsychotic. In 302 pregnancies, the women were treated with more than one category of antipsychotics.

\subsection{Time Trends in Antipsychotic Prescriptions}

A total of 803 prescriptions of F-GAs and 2396 of S-GAs were filed during pregnancy in Sweden 2006-17. In this period, the yearly number of pregnant women prescribed F-GAs decreased with $30 \%$, whereas the prescriptions of S-GAs increased by $300 \%$, from 91 to 367 yearly prescriptions during pregnancy. The three most prescribed antipsychotics were quetiapine, olanzapine and aripiprazole. The prescriptions rates over time are presented in Fig. 2 on a group level and individually for the S-GAs in Fig. 3.

\subsection{Gestational Diabetes and Foetal Growth}

When compared with women without antipsychotic treatment during pregnancy, the crude risk for GDM was significantly increased in the group of women treated with HR S-GAs and in women treated with F-GAs but not in women treated with other S-GAs. After adjustment for age, parity, smoking and BMI, only the women treated with HR S-GAs had an increased risk of GDM (Table 2). Increased BMI was strongly 
Table 1 Background characteristics of the study population

\begin{tabular}{|c|c|c|c|c|c|c|c|}
\hline & \multicolumn{2}{|c|}{$\begin{array}{l}\text { Antipsychotic use } \\
\text { during pregnancy, } \\
n=2677\end{array}$} & \multicolumn{2}{|c|}{$\begin{array}{l}\text { Antipsychotics before } \\
\text { or after but not dur- } \\
\text { ing pregnancy, } n= \\
34,492\end{array}$} & \multicolumn{2}{|c|}{$\begin{array}{l}\text { No antipsychotic use } \\
\text { during pregnancy }^{\mathrm{a}}, n= \\
1,296,539\end{array}$} & \multirow[t]{2}{*}{$\begin{array}{l}P \text {-value for het- } \\
\text { erogenicity between } \\
\text { groups }{ }^{b}\end{array}$} \\
\hline & $n$ & $\%$ & $n$ & $\%$ & $n$ & $\%$ & \\
\hline Year of childbirth & & & & & & & $<0.001$ \\
\hline $2006-10$ & 1013 & 37.8 & 19,279 & 55.9 & 630,942 & 48.7 & \\
\hline 2011-17 & 1664 & 62.2 & 15,213 & 44.1 & 665,597 & 51.3 & \\
\hline Maternal age, years & & & & & & & $<0.001$ \\
\hline$<20$ & 70 & 2.6 & 1059 & 3.1 & 26,613 & 2.1 & \\
\hline $20-35$ & 1883 & 70.3 & 26,638 & 77.2 & 991,018 & 76.4 & \\
\hline $35+$ & 724 & 27.0 & 6795 & 19.7 & 278,908 & 21.5 & \\
\hline Parity & & & & & & & $<0.001$ \\
\hline Primipara & 1891 & 70.6 & 20,727 & 60.1 & 818,330 & 63.1 & \\
\hline Multipara & 786 & 29.4 & 13,764 & 39.9 & 470,320 & 36.3 & \\
\hline Maternal BMI in early pregnancy & & & & & & & $<0.001$ \\
\hline$<18.5$ & 51 & 1.9 & 928 & 2.7 & 29,242 & 2.3 & \\
\hline $18.5-24.9$ & 1015 & 37.9 & 16,356 & 47.4 & 705,995 & 54.5 & \\
\hline $25-29.9$ & 772 & 28.8 & 8516 & 24.7 & 306,678 & 23.7 & \\
\hline$\geq 30$ & 618 & 23.1 & 5723 & 16.6 & 153,350 & 11.8 & \\
\hline Unknown & 221 & 8.3 & 2969 & 8.6 & 101,271 & 7.8 & $<0.001$ \\
\hline Maternal smoking in early pregnancy & & & & & & & $<0.001$ \\
\hline No & 1818 & 67.9 & 26,774 & 77.6 & $1,154,817$ & 89.1 & \\
\hline Yes & 733 & 27.4 & 5939 & 17.2 & 73,287 & 5.7 & \\
\hline Missing information & 126 & 4.7 & 1779 & 5.2 & 68,435 & 5.3 & 0.249 \\
\hline Maternal country of birth & & & & & & & $<0.001$ \\
\hline Sweden & 2018 & 75.4 & 27,655 & 80.2 & 956,473 & 73.8 & \\
\hline Other Nordic & 123 & 4.6 & 946 & 2.7 & 52,169 & 4.0 & \\
\hline Non-Nordic & 525 & 19.6 & 5844 & 16.9 & 263,103 & 20.3 & \\
\hline Maternal cohabitation & & & & & & & $<0.001$ \\
\hline Not living with the father of the child & 657 & 24.5 & 4824 & 14.0 & 80,275 & 6.2 & \\
\hline \multicolumn{8}{|l|}{ Maternal disease } \\
\hline Hypothyroidism & 122 & 4.6 & 973 & 2.8 & 27,672 & 2.1 & $<0.001$ \\
\hline Essential hypertension & 15 & 0.6 & 182 & 0.5 & 5130 & 0.4 & $<0.001$ \\
\hline \multicolumn{8}{|l|}{ Use of other neurotropic drugs } \\
\hline Lithium (N05A N01) & 124 & 4.6 & 292 & 0.8 & 294 & 0.0 & $<0.001$ \\
\hline Opioids (N02A) & 44 & 1.6 & 604 & 1.8 & 5352 & 0.4 & $<0.001$ \\
\hline Antiepileptics (N03A) & 215 & 8.0 & 725 & 2.1 & 3714 & 0.3 & $<0.001$ \\
\hline Antidepressants (N06A) & 755 & 28.2 & 4409 & 12.8 & 28,335 & 2.2 & $<0.001$ \\
\hline Psychostimulants (N06B) & 88 & 3.3 & 328 & 1.0 & 1118 & 0.1 & $<0.001$ \\
\hline Anxiolytics, sedatives (N05B, N05C) & 436 & 16.3 & 1429 & 4.1 & 6049 & 0.5 & $<0.001$ \\
\hline Mild anxiolytics, sedatives and antiemetics ${ }^{c}$ & 366 & 13.7 & 2516 & 7.3 & 26,938 & 2.1 & $<0.001$ \\
\hline
\end{tabular}

$B M I$ body mass index

${ }^{a}$ Includes all pregnant women during the study period who have not used antipsychotics during pregnancy, including those from the control group "antipsychotics before or after but not during pregnancy". However, these women were extracted from the group in the statistical analysis of the heterogenicity between the groups

${ }^{\mathrm{b}} \mathrm{Chi}^{2}$. A comparison between women using antipsychotics during pregnancy, women who used antipsychotics before or after but not during the actual pregnancy and women who have never used antipsychotics

${ }^{c}$ Including promethazine (R06AD02, R06AD52), alimemazine (R06AD01), dixyrazine (N05A B01), prochlorperazine (N05A B04) and melperone (N05A D03) 


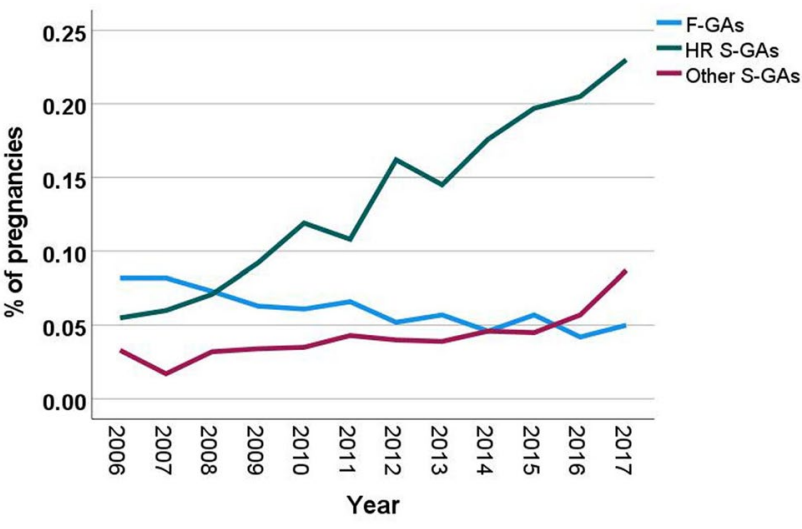

Fig. 2 Time trend in the percentage of pregnant women in Sweden receiving a prescription of the second-generation antipsychotics quetiapine, olanzapine and clozapine with high metabolic risks (HR S-GAs), other second-generation antipsychotics (other S-GAs) or first-generation antipsychotics (F-GAs)

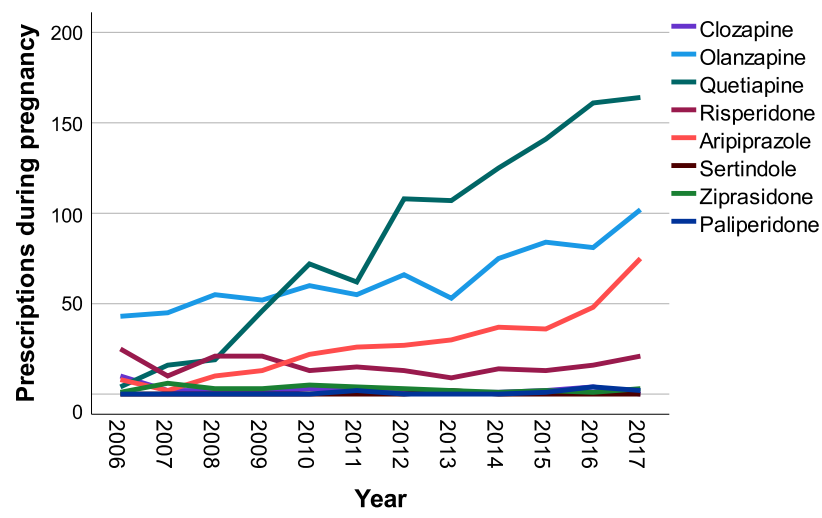

Fig. 3 Yearly prescription rates of second-generation antipsychotics during pregnancy years 2006-17

associated with GDM, and smoking was negatively associated with GDM. Women treated with HR S-GAs had a significantly increased risk for GDM also when compared with women treated with antipsychotics before and/or after but not during the actual pregnancy. An analysis without adjustment for BMI gave an adjusted RR for GDM of $1.6(95 \% \mathrm{CI}$ 1.0-2.5) for women treated with F-GAs, 2.0 (95\% CI 1.5-2.7) for women treated with HR S-GAs and 1.5 (95\% CI 0.9-2.5) for women treated with other S-GAs when compared with the women not treated during pregnancy. The association between antipsychotic use and GDM was also studied separately in BMI strata. The adjusted RR for GDM for women treated with HR S-GAs compared to women not treated during pregnancy in normal weight women (BMI <25) was $1.3(95 \%$ CI 0.5-3.6), in overweight women (BMI 25-30) was 2.4 (95\% CI 1.4-3.9) and in obese women (BMI > 30) was 1.4 (95\% CI 0.9-2.2). Even though the BMI-strata-specific RRs for GDM differed, no significant heterogeneity was detected between the strata $(p=0.298)$. The risk for GDM was not increased after use of HR SGAs in late pregnancy compared to early pregnancy only, adjusted RR 1.3 (95\% CI 0.7-2.3), $p=0.345$.

The risk for the child being LGA was increased for women treated with HR S-GAs, both when compared with women not treated during pregnancy and when compared with women treated with antipsychotics before and/or after but not during pregnancy. The risk for the child being SGA was not increased after use of any group of antipsychotics after adjustment for age, parity, smoking and BMI (Tables 2, $3)$. Adjustment for concomitant medication with other psychotropic drugs listed in Table 1 altered the risk estimates for GDM, SGA and LGA only marginally.

\subsection{Other Pregnancy Outcomes}

The risk of moderate to late prematurity (gestational age 32 to $36+6$ weeks) was increased for women treated with antipsychotics, when compared with both women not treated during pregnancy and with the comparison group of women treated with antipsychotics before or after but not during the actual pregnancy. The risk of caesarean section, both emergency and planned, was increased compared with women not treated during pregnancy but only marginally increased when compared with the comparison group. The risks for pre-eclampsia and perinatal death were not increased after antipsychotic use during pregnancy (Table 4).

\section{Discussion}

\subsection{Key Results}

Treatment with the HR S-GAs clozapine, quetiapine and olanzapine during pregnancy was associated with increased risks of GDM and the child being LGA. The other S-GAs did not share this same metabolic risk increase, possibly explained by the high percentage of women treated with aripiprazole in that group. The crude risk for the child being SGA was also increased for the HR S-GA group, but the risk increase was not significant after adjustment for maternal factors. This might be explained by the high frequency of smokers in this group, as smoking is known to be strongly connected to intrauterine growth restriction [46].

The adjusted model where BMI was not adjusted for showed higher relative risks for GDM in women in all exposure groups compared with when BMI was adjusted for. Most S-GAs have weight gain as a common side effect and the risk for GDM is known to increase with increased BMI. Maternal BMI is therefore most likely mediating this correlation [33, 47]. However, as patients with severe psychiatric diagnoses tend to have increased BMI regardless of medication, BMI is 
Table 2 Risk Ratios for gestational diabetes and disturbances in foetal growth after treatment with F-GAs, the high metabolic risk S-GAs olanzapine, clozapine and quetiapine, and other S-GAs risperidone, aripiprazole, sertrindole, paliperidone and ziprasidone

\begin{tabular}{|c|c|c|c|c|c|c|c|c|}
\hline \multirow[t]{2}{*}{ Outcomes } & \multicolumn{4}{|c|}{ Use vs no use during pregnancy ${ }^{\mathrm{a}}$} & \multicolumn{4}{|c|}{ Use during pregnancy vs use before/after pregnancy } \\
\hline & Crude RR & $95 \% \mathrm{CI}$ & Adjusted RR ${ }^{b}$ & $95 \% \mathrm{CI}$ & Crude RR & $95 \% \mathrm{CI}$ & Adjusted RR ${ }^{b}$ & $95 \% \mathrm{CI}$ \\
\hline \multicolumn{9}{|l|}{ F-GAs } \\
\hline Gestational diabetes & 1.86 & $1.17-2.93$ & 1.34 & $0.86-2.08$ & 1.65 & $1.05-2.58$ & 1.24 & $0.80-1.93$ \\
\hline Small for gestational age & 1.58 & $1.09-2.28$ & 1.25 & $0.86-1.80$ & 1.42 & $0.98-2.04$ & 1.20 & $0.83-1.73$ \\
\hline Large for gestational age & 0.82 & $0.53-1.25$ & 0.79 & $0.52-1.21$ & 0.72 & $0.47-1.10$ & 0.70 & $0.46-1.06$ \\
\hline \multicolumn{9}{|l|}{ High metabolic risk S-GAs } \\
\hline Gestational diabetes & 2.16 & $1.59-2.92$ & 1.77 & $1.33-2.37$ & 1.83 & $1.35-2.48$ & 1.62 & $1.20-2.12$ \\
\hline Small for gestational age & 1.57 & $1.23-2.02$ & 1.23 & $0.96-1.57$ & 1.38 & $1.07-1.77$ & 1.17 & $0.91-1.50$ \\
\hline Large for gestational age & 1.53 & $1.23-1.89$ & 1.58 & $1.28-1.96$ & 1.29 & $1.04-1.61$ & 1.32 & $1.06-1.63$ \\
\hline \multicolumn{9}{|l|}{ Other S-GAs } \\
\hline Gestational diabetes & 1.54 & $0.90-2.66$ & 1.14 & $0.68-1.92$ & 1.39 & $0.81-2.39$ & 0.97 & $0.57-1.67$ \\
\hline Small for gestational age & 1.12 & $0.68-1.82$ & 0.91 & $0.56-1.48$ & 1.02 & $0.63-1.65$ & 0.90 & $0.55-1.46$ \\
\hline Large for gestational age & 1.38 & $0.93-2.03$ & 1.33 & $0.90-1.95$ & 1.21 & $0.83-1.78$ & 1.15 & $0.78-1.69$ \\
\hline
\end{tabular}

$B M I$ body mass index, $C I$ confidence interval, $F$ - $G A s$ first-generation antipsychotics, $R R$ risk ratio, $S$ - $G A s$ second-generation antipsychotics

${ }^{a}$ All women not using antipsychotics during pregnancy. Sum of women who never used antipsychotics and women who used before/after but not during pregnancy

${ }^{\mathrm{b}}$ Adjusted for maternal age, parity, BMI and smoking

Table 3 Frequencies of gestational diabetes and foetal growth disturbances after treatment with F-GAs, HR S-GAs olanzapine, clozapine, and quetiapine and other S-GAs (risperidone, aripiprazole, sertrindole, paliperidone and ziprasidone)

\begin{tabular}{|c|c|c|c|c|c|c|c|c|c|c|}
\hline \multirow[t]{2}{*}{ Outcomes } & \multicolumn{2}{|c|}{ F-GAs $(n=728)$} & \multicolumn{2}{|c|}{$\begin{array}{l}\text { HR S-GAs }(n= \\
1710)\end{array}$} & \multicolumn{2}{|c|}{$\begin{array}{l}\text { Other S-GAs }(n= \\
541)\end{array}$} & \multicolumn{2}{|c|}{$\begin{array}{l}\text { Use of any antip- } \\
\text { sychotic before/ } \\
\text { after pregnancy ( } n= \\
34,492)\end{array}$} & \multicolumn{2}{|c|}{$\begin{array}{l}\text { No antipsychotic } \\
\text { use during } \\
\text { pregnancy } \\
1,296,539)\end{array}$} \\
\hline & $n$ & $\%$ & $n$ & $\%$ & $n$ & $\%$ & $n$ & $\%$ & $n$ & $\%$ \\
\hline Gestational diabetes & 21 & 2.9 & 49 & 2.9 & 14 & 2.6 & 493 & 1.4 & 15,464 & 1.2 \\
\hline Small for gestational age & 30 & 4.1 & 66 & 3.9 & 17 & 3.1 & 929 & 2.7 & 30,102 & 2.3 \\
\hline Large for gestational age & 22 & 3.0 & 85 & 5.0 & 26 & 4.8 & 1410 & 4.1 & 41,873 & 3.2 \\
\hline
\end{tabular}

F-GAs first-generation antipsychotics, HR S-GAs high metabolic risk second-generation antipsychotics, $S$-GAs second-generation antipsychotics

${ }^{a}$ All women not using antipsychotics during pregnancy. Sum of women who never used antipsychotics and women who used before/after but not during pregnancy

also a confounder for the studied correlation [48]. In this study, BMI is adjusted for, as not doing so would over-estimate the association between the drug treatment and the outcome. This study shows a significant risk increase for GDM even after adjustment for BMI, which other studies with smaller sample sizes have not been able to demonstrate [10, 33, 34].

The stratification by BMI in this study showed similar tendencies as were found previously [33], with a higher risk increase for GDM in overweight women treated with antipsychotics than in normal weight and obese women. However, the CIs for the risk estimates were wide and the difference between the strata was not statistically significant. It would have also been hard to explain why this would be the case from a biological standpoint.
This study also confirmed the slightly increased risk for prematurity suggested by previous studies [37, 49-52]. There is probably an effect of the underlying disease and lifestyle factors behind the association seen between an increased risk for moderate to late prematurity. The frequency of moderate to late prematurity was also increased amongst the women treated with antipsychotics before or after but not during the actual pregnancy. This is in line with the results of a study on antipsychotic use during pregnancy with a sibling analysis [53]. The risk increase for caesarean sections was clearly decreased when the women treated with antipsychotics were compared with the control group of women treated with antipsychotics before or after but not during the pregnancy. This suggests 


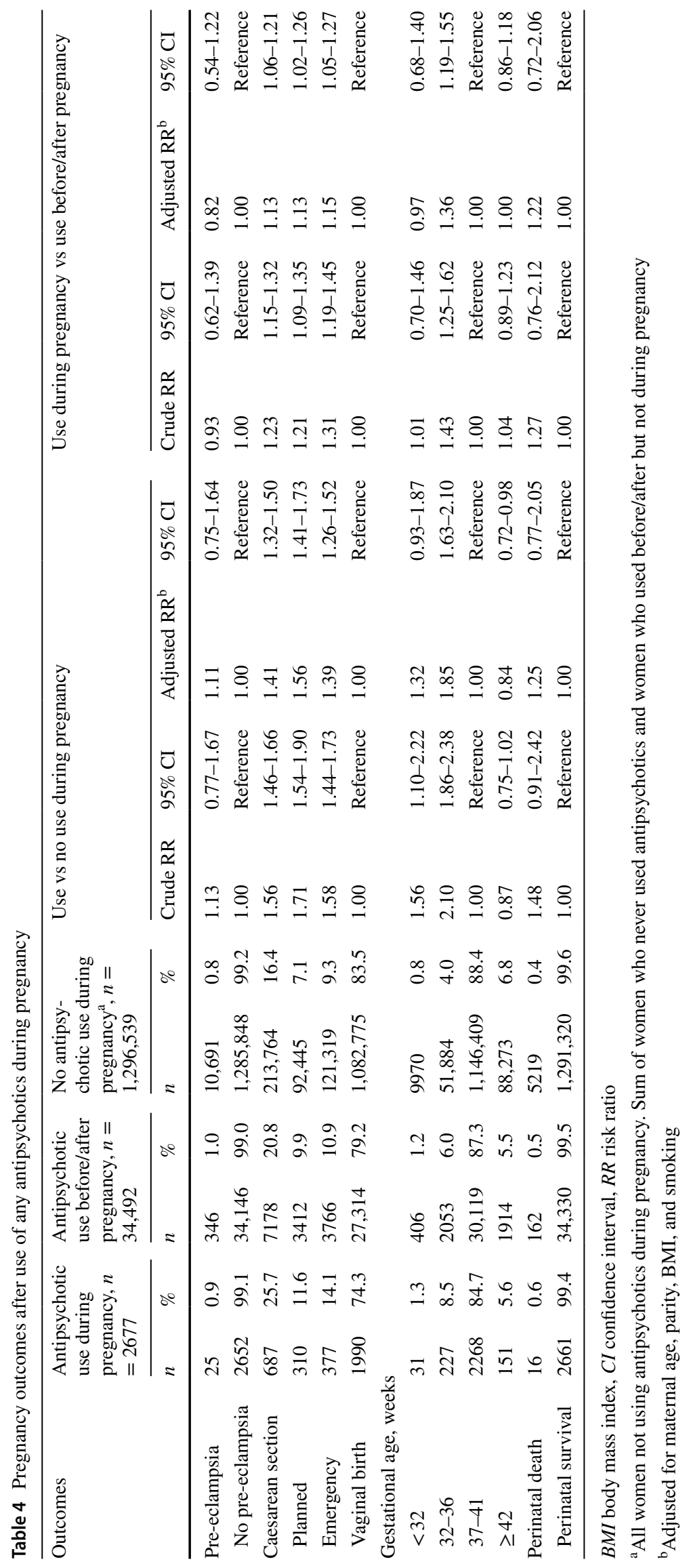


that the increased risk for caesarean section might not necessarily be associated with the medication itself, but the underlying disease and its associated risks, and lifestyle factors.

\subsection{Strengths and Limitations}

The nationwide health registers used in this study have a 98\% coverage of pregnancies in Sweden. Therefore, studies like this have strengths such as completeness of data, almost no sampling bias and large sample sizes. However, a methodological limitation for pharmacoepidemiologic studies is basing the exposure variable only on filed drug prescriptions, therefore not reporting the actual drug intake and excluding drugs prescribed in hospitals. The latter one is most likely not a significant source of bias when it comes to antipsychotics, as they are rarely used solely in hospitals without a following prescription for continuous use after discharge. The current project did not have access to information on the duration of drug treatment and the drug dosage. Therefore, register-based studies, such as this, lack the ability to study whether the risks of developing the studied outcomes are dose dependent.

As the information on drug use inherits some uncertainty, some women might have been erroneously misclassified to the wrong exposure group in this study. Some women could have used previously purchased drugs during pregnancy and thus been erroneously classified as non-exposed, whereas some women who purchased the drugs may not have used them during pregnancy. As information on drug use was recorded before the pregnancy outcome was known, the misclassification is unbiased by pregnancy outcome, and therefore unlikely to seriously bias the results.

Another common limitation to register-based studies is how to control for the severity of the underlying disease and its associated lifestyle and psychosocial factors. One of the strengths of this study is addressing this issue by having a comparison group of women with prescriptions of antipsychotics before and/or after but not during the pregnancy. Table 1 shows that the background characteristics of the exposed group were, to some extent, mirrored in the comparison group. However, to fully adjust for confounding by indication and disease severity in this type of study may not be possible.

\subsection{Interpretation}

The results of this study are in line with other recent studies. A large American study showed an increased risk for GDM for women treated with olanzapine or quetiapine continuing their treatment throughout pregnancy compared with discontinuers in early pregnancy, and a recent
Finnish register-based study showed a similar risk increase for GDM for women treated with S-GAs as this study, when compared with women treated with F-GAs $[19,30]$. Despite these studies not being fully comparable because of different control groups and statistical models, all three show a similar risk increase for GDM after treatment with S-GAs.

\subsection{Generalizability}

The risk for GDM varies widely internationally. The absolute risk of GDM in this study is low in all groups, $1.2 \%$ in the untreated women and $2.9 \%$ in women treated with HR S-GAs. Other studies from both Europe and the USA have presented a prevalence of GDM of 5-25\% both in women with and without treatment with antipsychotics $[15,19$, 30]. One explanation for this large variation is the different definitions and diagnostic thresholds used for the diagnosis of GDM [15]. In Sweden, there was a lack of consensus regarding screening for GDM until 2015 when the national guidelines were published, meaning that women with GDM might have gone undiagnosed [28, 29, 54, 55]. However, the low screening rates should not affect the generalizability of the results of this study as the potential misclassification by underdiagnosis of GDM should be similar across the different exposure groups. This hypothesis is reinforced by the similar studies from the USA and Finland leading to similar results to this study $[19,30]$.

\section{Conclusions}

Use of quetiapine, olanzapine and clozapine during pregnancy is associated with an increased risk of GDM and the child being LGA. Use of any antipsychotic during pregnancy was associated with slightly increased risks of moderate to late prematurity and caesarean section. These risk increases might be caused by underlying factors rather than the medication itself. We recommend screening for GDM in women treated with quetiapine, olanzapine or clozapine, but not discontinuation of treatment. In the case of starting a new antipsychotic treatment in pregnancy or, preferably, before a planned pregnancy, some other antipsychotic might be considered to avoid these metabolic risks.

\section{Declarations}

Funding Funding for this article was received from Region Stockholm, ALF project number 573301 (EH, KW, LF), Department of Neonatology at Karolinska University Hospital, General Maternity Hospital Foundation, Samaritan Foundation for Paediatric Research, Lilla Barnets Fond (EH), and Sven Jerring Foundation (LF). The funders did not 
take part in conducting the research or writing the paper. Open access funding was provided by Karolinska Institute.

Conflict of interest EH, LF, UN, KW and KK declare that they have no competing interests.

Ethics approval The study was approved by the Regional Ethical Review Board in Lund (dnr. 2013/342-31/5).

Consent to participate Not applicable.

Consent for publication Not applicable.

Availability of data and material Data from the Swedish registers are protected, but some aggregated data can be available on request from the authors.

\section{Code availability Not applicable.}

Author contributions KK conceptualized and designed the study, was responsible for the data collection, carried out the initial analyses, and reviewed and revised the manuscript. EH conceptualized and designed the study and drafted the initial manuscript. UN, LF and KW conceptualized and designed the study and critically reviewed and revised the manuscript. All authors approved the final manuscript as submitted and agree to be accountable for all aspects of the work outlined in the manuscript.

Open Access This article is licensed under a Creative Commons Attribution-NonCommercial 4.0 International License, which permits any non-commercial use, sharing, adaptation, distribution and reproduction in any medium or format, as long as you give appropriate credit to the original author(s) and the source, provide a link to the Creative Commons licence, and indicate if changes were made. The images or other third party material in this article are included in the article's Creative Commons licence, unless indicated otherwise in a credit line to the material. If material is not included in the article's Creative Commons licence and your intended use is not permitted by statutory regulation or exceeds the permitted use, you will need to obtain permission directly from the copyright holder. To view a copy of this licence, visit http://creativecommons.org/licenses/by-nc/4.0/.

\section{References}

1. Damkier P, Christensen LS, Broe A. Patterns and predictors for prescription of psychotropics and mood-stabilizing antiepileptics during pregnancy in Denmark 2000-2016. Br J Clin Pharmacol. 2018;84(11):2651-62. https://doi.org/10.1111/bcp. 13732 .

2. Alexander GC, Gallagher SA, Mascola A, et al. Increasing offlabel use of antipsychotic medications in the United States, 19952008. Pharmacoepidemiol Drug Saf. 2011;20(2):177-84. https:// doi.org/10.1002/pds.2082.

3. Stephenson CP, Karanges E, McGregor IS. Trends in the utilisation of psychotropic medications in Australia from 2000 to 2011. Aust N Z J Psychiatry. 2013;47(1):74-87. https://doi.org/10.1177/ 0004867412466595.

4. Park Y, Huybrechts KF, Cohen JM, et al. Antipsychotic medication use among publicly insured pregnant women in the United States. Psychiatr Serv. 2017;68(11):1112-9. https://doi.org/10. 1176/appi.ps.201600408
5. Grande I, Berk M, Birmaher B, et al. Bipolar disorder. Lancet. 2016;387(10027):1561-72. https://doi.org/10.1016/s01406736(15)00241-x

6. Dodd S, Berk M. The pharmacology of bipolar disorder during pregnancy and breastfeeding. Expert Opin Drug Saf. 2004;3(3):221-9. https://doi.org/10.1517/eods.3.3.221.31074.

7. Schaffer AL, Zoega H, Tran DT, et al. Trajectories of antipsychotic use before and during pregnancy and associated maternal and birth characteristics. Aust N Z J Psychiatry. 2019;53(12):1208-21. https://doi.org/10.1177/0004867419847764.

8. Rummel-Kluge C, Komossa K, Schwarz S, et al. Head-to-head comparisons of metabolic side effects of second generation antipsychotics in the treatment of schizophrenia: a systematic review and meta-analysis. Schizophr Res. 2010;123(2-3):225-33. https:// doi.org/10.1016/j.schres.2010.07.012.

9. Holder SD, Edmunds AL, Morgan S. Psychotic and bipolar disorders: antipsychotic drugs. FP Essent. 2017;455:23-9.

10. Bodén R, Lundgren M, Brandt L, et al. Antipsychotics during pregnancy: relation to fetal and maternal metabolic effects. Arch Gen Psychiatry. 2012;69(7):715-21. https://doi.org/10.1001/archg enpsychiatry.2011.1870.

11. Toh S, Li Q, Cheetham TC, et al. Prevalence and trends in the use of antipsychotic medications during pregnancy in the U.S., 2001-2007: a population-based study of 585,615 deliveries. Arch Womens Ment Health. 2013;16(2):149-57. https://doi.org/10. 1007/s00737-013-0330-6.

12. Hirsch L, Yang J, Bresee L, et al. Second-generation antipsychotics and metabolic side effects: a systematic review of populationbased studies. Drug Saf. 2017;40(9):771-81. https://doi.org/10. 1007/s40264-017-0543-0.

13. Henderson DC, Doraiswamy PM. Prolactin-related and metabolic adverse effects of atypical antipsychotic agents. J Clin Psychiatry. 2008;69(Suppl. 1):32-44.

14. Pillinger T, McCutcheon RA, Vano L, et al. Comparative effects of 18 antipsychotics on metabolic function in patients with schizophrenia, predictors of metabolic dysregulation, and association with psychopathology: a systematic review and network metaanalysis. Lancet Psychiatry. 2020;7(1):64-77. https://doi.org/10. 1016/s2215-0366(19)30416-x.

15. Zhu Y, Zhang C. Prevalence of gestational diabetes and risk of progression to type 2 diabetes: a global perspective. Curr Diab Rep. 2016;16(1):7. https://doi.org/10.1007/s11892-015-0699-x.

16. Uguz F. Antipsychotic use during pregnancy and the risk of gestational diabetes mellitus: a systematic review. J Clin Psychopharmacol. 2019;39(2):162-7. https://doi.org/10.1097/JCP.00000 00000001002 .

17. Zhang C, Ning Y. Effect of dietary and lifestyle factors on the risk of gestational diabetes: review of epidemiologic evidence. Am J Clin Nutr. 2011;94(Suppl_6):1975S-S1979. https://doi.org/10. 3945/ajen.110.001032.

18. Kim MK, Lee SM, Bae S-H, et al. Socioeconomic status can affect pregnancy outcomes and complications, even with a universal healthcare system. Int J Equity Health. 2018;17(1):2. https://doi. org/10.1186/s12939-017-0715-7.

19. Ellfolk M, Leinonen MK, Gissler M, et al. Second-generation antipsychotics and pregnancy complications. Eur J Clin Pharmacol. 2020;76(1):107-15. https://doi.org/10.1007/ s00228-019-02769-z.

20. Petersen I, Sammon CJ, McCrea RL, et al. Risks associated with antipsychotic treatment in pregnancy: comparative cohort studies based on electronic health records. Schizophr Res. 2016;176(23):349-56. https://doi.org/10.1016/j.schres.2016.07.023.

21. Petersen I, McCrea RL, Sammon CJ, et al. Risks and benefits of psychotropic medication in pregnancy: cohort studies based on UK electronic primary care health records. Health Technol Assess. 2016;20(23):1-176. https://doi.org/10.3310/hta20230. 
22. Gentile S. Antipsychotic therapy during early and late pregnancy: a systematic review. Schizophr Bull. 2010;36(3):518-44. https:// doi.org/10.1093/schbul/sbn107.

23. Farahvar S, Walfisch A, Sheiner E. Gestational diabetes risk factors and long-term consequences for both mother and offspring: a literature review. Expert Rev Endocrinol Metab. 2019;14(1):6374. https://doi.org/10.1080/17446651.2018.1476135.

24. Habermann F, Fritzsche J, Fuhlbruck F, et al. Atypical antipsychotic drugs and pregnancy outcome: a prospective, cohort study. J Clin Psychopharmacol. 2013;33(4):453-62. https://doi.org/10. 1097/JCP.0b013e318295fe12.

25. McKenna K, Koren G, Tetelbaum M, et al. Pregnancy outcome of women using atypical antipsychotic drugs: a prospective comparative study. J Clin Psychiatry. 2005;66(4):444-9 (quiz 546).

26. Newport DJ, Calamaras MR, DeVane CL, et al. Atypical antipsychotic administration during late pregnancy: placental passage and obstetrical outcomes. Am J Psychiatry. 2007;164(8):1214-20. https://doi.org/10.1176/appi.ajp.2007.06111886.

27. HAPO Study Cooperative Research Group, Metzger BE, Lowe LP, Dyer AR, Trimble ER, Chaovarindr U, et al. Hyperglycemia and adverse pregnancy outcomes. N Engl J Med. 2008;358(19):19912002. https://doi.org/10.1056/nejmoa0707943.

28. Persson M, Winkvist A, Mogren I. Surprisingly low compliance to local guidelines for risk factor based screening for gestational diabetes mellitus: a population-based study. BMC Pregnancy Childbirth. 2009;9(1):53. https://doi.org/10.1186/1471-2393-9-53.

29. Ignell $\mathrm{C}$, Claesson $\mathrm{R}$, Anderberg $\mathrm{E}$, et al. Trends in the prevalence of gestational diabetes mellitus in southern Sweden, 2003-2012. Acta Obstet Gynecol Scand. 2014;93(4):420-4. https://doi.org/ 10.1111/aogs.12340.

30. Park Y, Hernandez-Diaz S, Bateman BT, et al. Continuation of atypical antipsychotic medication during early pregnancy and the risk of gestational diabetes. Am J Psychiatry. 2018;175(6):56474. https://doi.org/10.1176/appi.ajp.2018.17040393.

31. Frayne J, Nguyen T, Bennett K, et al. The effects of gestational use of antidepressants and antipsychotics on neonatal outcomes for women with severe mental illness. Aust N Z J Obstet Gynaecol. 2017;57(5):526-32. https://doi.org/10.1111/ajo.12621.

32. Bellet F, Beyens MN, Bernard N, et al. Exposure to aripiprazole during embryogenesis: a prospective multicenter cohort study. Pharmacoepidemiol Drug Saf. 2015;24(4):368-80. https://doi.org/ 10.1002/pds.3749.

33. Panchaud A, Hernandez-Diaz S, Freeman MP, et al. Use of atypical antipsychotics in pregnancy and maternal gestational diabetes. J Psychiatr Res. 2017;95:84-90. https://doi.org/10.1016/j.jpsyc hires.2017.07.025.

34. Vigod SN, Gomes T, Wilton AS, et al. Antipsychotic drug use in pregnancy: high dimensional, propensity matched, population based cohort study. BMJ. 2015;350: h2298. https://doi.org/10. 1136/bmj.h2298.

35. Kallen B, Borg N, Reis M. The use of central nervous system active drugs during pregnancy. Pharmaceuticals (Basel). 2013;6(10):1221-86. https://doi.org/10.3390/ph6101221.

36. Newham JJ, Thomas SH, MacRitchie K, et al. Birth weight of infants after maternal exposure to typical and atypical antipsychotics: prospective comparison study. Br J Psychiatry. 2008;192(5):333-7. https://doi.org/10.1192/bjp.bp.107.041541.

37. Sadowski A, Todorow M, Yazdani Brojeni P, et al. Pregnancy outcomes following maternal exposure to second-generation antipsychotics given with other psychotropic drugs: a cohort study. BMJ Open. 2013. https://doi.org/10.1136/bmjopen-2013-003062.

38. Kulkarni J, Storch A, Baraniuk A, et al. Antipsychotic use in pregnancy. Expert Opin Pharmacother. 2015;16(9):1335-45. https:// doi.org/10.1517/14656566.2015.1041501.

39. Petersen I, McCrea RL, Osborn DJP, et al. Discontinuation of antipsychotic medication in pregnancy: a cohort study. Schizophr
Res. 2014;159(1):218-25. https://doi.org/10.1016/j.schres.2014. 07.034.

40. Viguera AC, Whitfield T, Baldessarini RJ, et al. Risk of recurrence in women with bipolar disorder during pregnancy: prospective study of mood stabilizer discontinuation. Am J Psychiatry. 2007;164(12):1817-24. https://doi.org/10.1176/appi.ajp.2007. 06101639.

41. Larsen ER, Saric K. Pregnancy and bipolar disorder: the risk of recurrence when discontinuing treatment with mood stabilisers: a systematic review. Acta Neuropsychiatr. 2017;29(5):259-66. https://doi.org/10.1017/neu.2016.60.

42. EpC. The Swedish Medical Birth Register: a summary of content and quality. https://www.socialstyrelsen.se/globalassets/share point-dokument/artikelkatalog/ovrigt/2003-112-3_20031123. pdf. Accessed 9 Nov 2020.

43. Wettermark B, Hammar N, Michaelfored C, et al. The new Swedish Prescribed Drug Register: opportunities for pharmacoepidemiological research and experience from the first six months. Pharmacoepidemiol Drug Saf. 2007;16(7):726-35. https://doi. org/10.1002/pds.1294.

44. Sidhu HS, Srinivas R, Sadhotra A. Evaluate the effects of longterm valproic acid treatment on metabolic profiles in newly diagnosed or untreated female epileptic patients: a prospective study. Seizure. 2017;48:15-21. https://doi.org/10.1016/j.seizure.2017. 03.007.

45. Maršál K, Persson PH, Larsen T, et al. Intrauterine growth curves based on ultrasonically estimated foetal weights. Acta Paediatr. 1996;85(7):843-8. https://doi.org/10.1111/j.1651-2227.1996. tb14164.x.

46. Reeves S, Bernstein I. Effects of maternal tobacco-smoke exposure on fetal growth and neonatal size. Expert Rev Obstet Gynecol. 2008;3(6):719-30. https://doi.org/10.1586/17474108.3. 6.719 .

47. Newcomer JW. Metabolic considerations in the use of antipsychotic medications: a review of recent evidence. J Clin Psychiatry. 2007;68(Suppl. 1):20-7.

48. Allison DB, Newcomer JW, Dunn AL, et al. Obesity among those with mental disorders: a National Institute of Mental Health meeting report. Am J Prev Med. 2009;36(4):341-50. https://doi.org/ 10.1016/j.amepre.2008.11.020.

49. Nulman I. The effects of the new antipsychotic medications on mothers and babies. J Popul Ther Clin Pharmacol. 2014;21(3):e542-7.

50. Gentile S, Fusco ML. Schizophrenia and motherhood. Psychiatry Clin Neurosci. 2019;73(7):376-85. https://doi.org/10.1111/pcn. 12856.

51. Kulkarni J, Worsley R, Gilbert H, et al. A prospective cohort study of antipsychotic medications in pregnancy: the first 147 pregnancies and 100 one year old babies. PLoS ONE. 2014;9(5): e94788. https://doi.org/10.1371/journal.pone.0094788.

52. Terrana N, Koren G, Pivovarov J, et al. Pregnancy outcomes following in utero exposure to second-generation antipsychotics: a systematic review and meta-analysis. J Clin Psychopharmacol. 2015;35(5):559-65. https://doi.org/10.1097/JCP.0000000000 000391.

53. Wang Z, Chan AYL, Coghill D, et al. Association between prenatal exposure to antipsychotics and attention-deficit/hyperactivity disorder, autism spectrum disorder, preterm birth, and small for gestational age. JAMA Intern Med. 2021;181(10):1332. https:// doi.org/10.1001/jamainternmed.2021.4571.

54. Lindqvist M, Persson M, Lindkvist M, et al. No consensus on gestational diabetes mellitus screening regimes in Sweden: pregnancy outcomes in relation to different screening regimes 2011 to 2012, a cross-sectional study. BMC Pregnancy Childbirth. 2014;14(1):185. https://doi.org/10.1186/1471-2393-14-185.

55. Socialstyrelsen. Gränsvärden för graviditetsdiabetes. 2015. 